\title{
Integrative Games as the Technique of Technical University Students' Professional Competences Formation in the Field of Health and Safety
}

Elena N. Prokofieva

The Institute of Pedagogic and Psychology of Professional Education of Russian Academy of Education, 420039, Kazan, Russi Email:solo73@inbox.ru

Alexander Y. Shirnin

Konstantin A. Smotrin

Volga State University of Technology, 424000, Yoshkar-Ola, Russia

Gulfiya R. Tuisina

Sibay institute (branch) of Bashkir State University, 453838, Sibay, Russia

Ivan V. Pavlov

Galina G. Tenyukova

Chuvash State Pedagogical University named after I.Y. Yakovlev, 428032, Cheboksary, Russia

Natalia A. Filina

Volga State University of Technology, 424000, Yoshkar-Ola, Russia

Doi:10.5901/mjss.2015.v6n2s3p64

\section{Abstract}

In order to prevent and minimize the consequences of global environmental change caused by ecological, technological and economic problems, there need professionals with high-quality training in the field of health and safety. The article defines the special aspects of technical students' professional competences formation of in the field of health and safety in the modern world. The authors propose a set of integrative games boosting the learning process, creating simulated professional activities (situations), making it possible to develop skills and influence the relationships of participants and ensuring the formation of social and professional activities and readiness for work. This article is intended for teachers, psychologists, researchers, potential employers, specialists in the field of health and safety.

Keywords: higher education; professional competences; integrative games; health and safety; emergency situations.

\section{Introduction}

\subsection{Background}

Prevention of emergency situations is one of the main directions of the implemented state policy. In order to reduce the risks in the technosphere, to prevent and mitigate disasters, they need professionals with high-quality training in the field of health and safety in accordance with the requirements of scientific and technological progress. Implementation of regulatory, institutional, engineering and technical, economic, social, scientific and other activities aimed at prevention and reduction of accidents and mitigation of their consequences is carried out by persons authorized to solve problems in the field of security, civil defense, forecasting and recovery of emergency situations of natural and man-caused disasters and fire safety (Ivanov et al., 2015; Shaidullina et al., 2014; Shaidullina et al., 2015). In this regard, there is a need to enhance the professional training of technical university students in the field of health and safety and identify techniques that contribute to the formation of professional competences in the field of health and safety. One of the interactive forms 
of educational process organization of bachelors' training are integrative games, the use of which can ensure the formation of high-quality professional skills, as well as the ability to apply their knowledge, intellectual and practical skills in their future professional activity.

\subsection{Status of a problem}

Analysis of scientific literature shows that the problem of professional competences formation attracts the attention of scientists (Selevko, 1998; Baydenko, 2004; Zeer, 2005; Zimnya, 2006; Mukhametzyanova, 2010; Telegina et al., 2015; Ibragimov, 2011; Sakhieva et al., 2015 and others).

Scientific works in the field of health and safety systems in modern education (Belov, 2005; Grokholsky, 2005; Vorobiev, 2006; Muravyova, 2012) and person's safety culture formation have made a significant contribution to this study.

Considerable attention in the system of vocational training is given to exploring the possibilities of active and interactive techniques in the formation of professional competences of future specialists. In particular, there have been studied the issues of construction and use of game techniques use, role and place of game techniques in the system of higher vocational education (Efimova, 1982; Verbitsky, 1991; Pidkasistyi, 1996; Khairullina et al., 2015; Panfilova, 2006; Novikov, 2006 and others).

Due to the integrative processes in the system of vocational education integrative games become increasingly actual, they allow to ensure the integrity of some game forms and thus improve the efficiency of bachelor's training. However, such questions as a selection of the integrative games content, their functional structure, scenario planning, complex implementation, performance evaluation, systematic use and productivity conditions in terms of bachelors' vocational training in a technical university remain insufficiently studied.

\subsection{The research hypothesis}

The objectively existing need for the formation of technical universities bachelors' professional competences in the field of health and safety does not have a unique technique and methodic of implementation in the educational process of the university. The questions of game forms complex use in a close relationship and integration, both among themselves and with the stages of the whole process of bachelors' training, remain unexplored. According to our hypothesis, the efficiency of technical university bachelors' professional competences formation in the field of health and safety will be raised if in the learning process there is implemented the complex of integrative games which promote intensification; implementation of professional orientation of the educational process; interdisciplinary training and educational- industrial integration; development of the industrial skills of students.

\section{Experimental}

\subsection{The objectives of the research}

We have identified the following research objectives: 1) to determine the formation technique of technical university bachelors professional competences in the field of health and safety by means of integrative games; 2) to substantiate and develop the integrative games complex based on the principles of systemacity, continuity and professional orientation of training; 3 ) to introduce into the educational process and to verify the effectiveness of the integrative games complex as a formation means of technical university bachelors professional competences.

\subsection{Theoretical and empirical methods}

In order to examine the hypotheses of the study there were used theoretical (analysis, synthesis, generalization, classification, abstraction and others, applied to the State educational standards of higher professional education of the third generation, training and program documentation, training and methodic developments on this problem, law and regulatory acts governing educational activities, etc.); empirical (an interview, questionnaires, monitoring, a method of expert evaluations, teaching methods, an experiment); statistical (synthesis and processing of experimental data) methods. 


\subsection{The basis of the research}

The experimental work was carried out during the period from 2006 to 2013 on the basis of the Kazan National Research Technological University named after A.N. Tupolev (KNRTU - KAI). The experiment involved the students of I-IV courses acquiring disciplines in the field of health and safety (in total 211 students).

\subsection{The Stages of the research}

The study was conducted in three stages:

In the first stage the teaching experience of development of game training courses for different specialties has been studied, there were analyzed approaches to techniques of the technical university bachelors' vocational training from the standpoint of the professional competences formation; there were also studied qualification characteristics and the model of professional activity in the field of health and safety.

In the second stage there was designed the complex of integrative games, providing the gradual formation of professional competences and a technique of their implementation in bachelors' vocational training "Protection in emergency situations."

In the third stage an experiment was conducted to determine the level of bachelors' vocational training: an ascertaining stage (according to the current level of competence formation of students in the control group), a forming stage (according to the implementation of integrative games in the learning process) and a controlling stage (by definition of learning outcomes while using the complex of integrative games).

\subsection{Grounding for the use of integrative games complex in the educational process of bachelors' training}

Modern requirements for training specialists in the field of "Protection in emergency situations" have shown that it is necessary to ensure full readiness for professional work in the course of entire educational process, starting from the first year and ending with the defending of bachelors' final qualifying work.

Starting point for making professional decisions can and must serve the knowledge gained throughout life. That is, the earlier a person begins to form professional thinking, the more fundamental will be professional knowledge in the context of professional activities and more likely that his decisions taken in professional activities will be coordinated with the requirements of society. It is coordinated with the concept of Donald Sean, he called the concept of critical reasoning of practical activity (reflective practitioner perspective), which directs the experts - practitioners to rethink the results of their work, both during the creative process, and after receiving the final results. It should also be noted that technical university bachelors should be ready to take professional decisions and have a developed professional risk - thinking. Risk is a decision or an action from the perspective of subjective characteristics of uncertainty, where a person not only uncovers a mismatch of required and existing or potential opportunities in control of a situation, and where the evaluation of these opportunities potential is also uncertain. We are talking about the readiness for self-control actions in a deliberate incompleteness or unavailability of the necessary benchmarks, as well as the willingness to rely on one's potential.

In these circumstances, the teachers, performing technical specialists training, face the problem: to design such content of taught courses and to establish a system of didactic teaching aids, so a university graduate can smoothly adapt to modern conditions and become fully competitive in the labor market. The training of graduates of this level with the use of modern educational techniques is the main task of the Bachelor's programme.

In the bachelors' training the leading forms are active methods which recreate not only objective, but also a social content of future professional activity. The social context implies skills of social interaction and communication, sharing solutions, collective thinking, etc. During training the bachelor must perform the exact actions that are similar to those that will have a definite place in his career. The only difference is that the answers to the questions, which outcomes the initiated actions will lead to, in game situations gives a model of reality, not reality itself.

\section{Results}

3.1 The algorithm of developing the complex of integrative games for the professional competence formation of future engineers

The integrative games are defined as a kind of professional-oriented game activity simulating professional processes, modeling solutions to the tasks on the basis of interdisciplinary and education- production integration that contributes to 
the disclosure of personal potential of students (Prokofieva, 2012).

Integrative games character is explained by their certain features:

- firstly, the feature of integrative games is that learning occurs in situations as close to the real, so it permits the material, necessary for learning, to enter into the target activity, rather than in means.

- secondly, it is realizing not only the knowledge transfer but also training the skills use in practice, which in turn requires the presence/formation of certain personal qualities of students.

- thirdly, it is arranging the formation of new, qualitatively different orientation on training in emotionally intensive process of collective creative work.

- fourthly, there is interdisciplinary, educational-industrial integration.

We have developed the algorithm for designing the complex of integrative games comprising the following stages:

1. Definition of the professionally-oriented content reflecting the object of engineering labor, imitating professional activities and situations that arise in the professional field;

2. Definition of rules and scripts that define the relevance to the professional decision making process in the discipline framework;

3. Establishing necessary roles of participants (similar to positions in professional activities in the disciplinary safety);

4. Search for and justification of an important engineering problem in the field of safety and / or an industrial conflict situation;

5. Statement of a common industrial target for all participants in the game, and the definition of tasks for each participant able to influence by his/her actions on the achievement of final professional result, playing a certain role;

6. Formation (imitation) of industrial environment or its elements, recreating important conditions for competent professional decision making in the discipline.

\subsection{The complex of integrative games in the field of "Health and Safety"}

We have developed the complex of integrative games combined to form the professional competences during the whole training which simulates real professional connections and relationships, work situations and forms the conflict, industrial - professional situations during the game due to the divergence of the game participants' interests or a number of conditions of information uncertainty.

The complex of integrative games for the formation of professional competences of future engineers in the field of "Health and Safety" includes:

- an integrative game aimed at the ability to work in a team ("The team in extreme situations"), including simulation, research, vocational and communicative, professional activity of an engineer. The content of the integrative game "The team in extreme situations" is aimed at recognition, comparison, characteristics, disclosure of concepts, justification and application of professional knowledge in the field of protection from emergency situations (orientation stage). The game is played at the first course, 2-4- times a year, the situation varies.

- an integrative game aimed at identifying leadership qualities ("I am the leader"), including the simulation, organizational and managerial, professional activity of an engineer. During the integrative game there have been solving professional problems connected with the development of roles and specific of regional production, while the process of the integrative game there have played such important conditions as the geographic location of the object (excursions, photos, plans and maps of workshops, etc.), the presence of explosive industrial equipment and facilities for its service (installation phase). The game is played on the second year of studies, 2-4- times a year, the situation varies.

- an integrative game aimed at the formation and development of professional competences ("Emergency situation"), including the simulation of organizational, managerial and expert work of an engineer. During the game, the quasi-professional task is solved - an emergency situation emerged in the production accordingly the specifics of the regional branches of the economy (forming phase). The game is played on the third and fourth years of studies, 2-4- times a year, the situation varies.

The structure of the integrative games complex forms a set of elements: the subject of an integrative game, an integrative game scenario, integrative game participants, a role, functions of players, integrative game rules, diagnostics of the participants activities, as a result of manifestation of his professional competences. This complex is implementing throughout the bachelors' vocational training. For each course it is implementing its own type of an integrative game 
corresponding to the currently available professional knowledge and skills of students.

\subsection{The effectiveness of the implementation of the integrative games complex in the process of bachelors' training at the university}

The effectiveness of the implementation of the integrative games complex is characterized by the criteria, indicators and levels of professional competences formation, tested by us in bachelors' training in the field of "Protection in emergency situations." The authors have developed diagnostic tools to carry out the dynamic evaluation and visualization of the results of professional competences formation throughout the whole cycle of bachelors' training, including the adapted evaluation system with a total cumulative calculation of results of each bachelor's professional development according to the results.

Each criteria, determining the structural components of professional competences, can be formed on one of three evaluation levels: - a low one: personal abilities are not used to the full extent, or suppressed, resulting in a state of indecision, the difficulty in solving questions of different nature; the absence of a stable demand in special professional knowledge; - an average one: standard relation to professional activities; focus on cooperation, the presence of an independent trajectory of behavior based on personal abilities; - a high one: a comprehensive, versatile use of one's capabilities; responsibility for decisions, active actions, a constant readiness for self-improvement, an ability to adapt to any situation. Finally they give the integral evaluation - a compliance with the specialty determined by the level of each competence display and analysis of quasi-professional bachelor's activities within the simulation situations of integrative games.

The usage of this evaluating system allows: to obtain an estimation of achievement of competences individually for each bachelor concerning each integrative game; to diagnose gaps in the acquisition of knowledge and skills by bachelors during the traditional training and to implement their on-time correction; to determine the individual quality of each bachelor, their professional competences, behavior and ability to work in a team, leadership qualities, etc.

The level of bachelors' professional competences formation in the field of "Protection in emergency situations" can be identified by means of their successful participation in the integrative games. Playing of work situations, on the one hand, enriches their knowledge of safety, materials and expertise, and on the other, detects the presence or absence of professional competences of the bachelor in the field of "Protection in emergency situations". Thus, integrative games can be used both as a diagnostic tool and as a tool for the professional competences formation.

Comparative analysis of professional competences formation among the students having traditional learning (control group, 84 students) and those who use the integrative games complex (experimental group, 127 students) has shown the average $30 \%$ and more increase of level of professional competences formation (Figure 1)

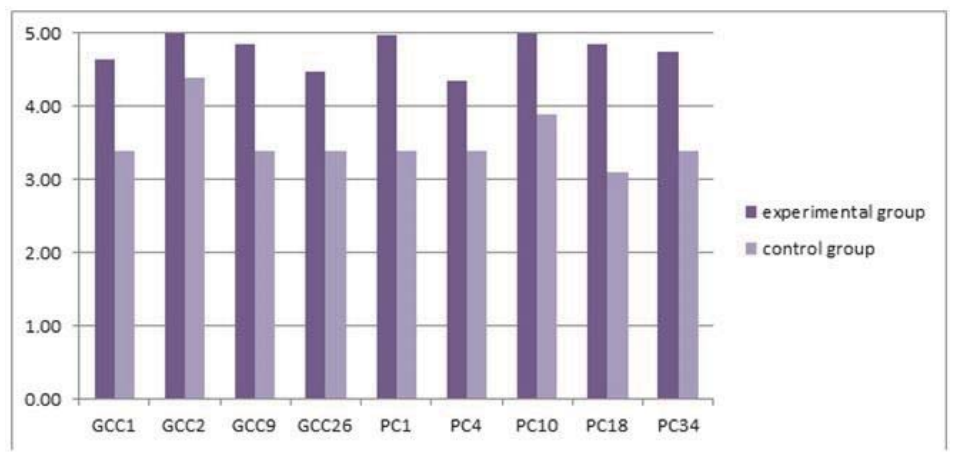

(GCC - general cultural competence, PC - professional competence)

Figure 1. Comparative analysis of professional competences formation of control and experimental groups (summarized data)

\section{Discussions}

During the process of integrative games happens the simulating of bachelors' professional activities, as well as the strategy for professional training in the university is developing in terms of future activities field - design-engineering; 
service-operational; organizational and managerial, expert, oversight and inspection-auditing; science-research. During the integrative games in the field of "Protection in emergency situations" it is developing a system of values which characterizes the integrity of the person, persistence in achieving goals, the attitude to oneself, to learning, to their future profession.

\section{Conclusions}

The bachelor in the field of "Protection in emergency situations" acquires the disciplinary content of training (knowledge, skills, professional experience) and, occupying a specific position in a communication system of participants in the educational process, follows established norms of social relations and actions to the extent that he is active here, is being formed and brought up as a person. During studies bachelors realize three basic forms of activity: learning, quasiprofessional and learning-professional, considering the fact that the transition from one form to another is determined by the logic of contextual organization of the learning content. Design, basement, organization of these forms of activity accounts requirements not only in the aspect of the studied science, which the educational process is based on, or didactics, but also in terms of professional activity, taking into account the social standardization of students activity. These requests from professional activities are system forming which determine the training technique.

\section{Acknowledgments}

The authors thank all participants of this study for their kind cooperation.

\section{References}

Baydenko, V.I. (2004) Competence in vocational training. Journal of Higher education in Russia, 11,4.

Belov, S.V. (2005).The Russian concept of continuous multi-level education in the field of life safety. Health and Safety, 4, 55-61.

Efimova, V.M. (1982). Game simulation expanded reproduction. Moscow State University,184.

Grokholsky, O.G. (2005). O safety culture personality and its formation. Magazine Knowledge. Understanding, 4, 60.

Ibragimov, G.I. (2011). Innovative learning technologies in the conditions of implementation of the competency approach. Journal of Innovations in Education, 4, 4.

Ivanov, V.G., Shaidullina, A.R., Drovnikov, A.S., Yakovlev, S.A. \& Masalimova, A.R. (2015). Regional Experience of Students' Innovative and Entrepreneurial Competence Forming. Asian Social Science, Vol. 11, No. 1, 35-40, doi:10.5539/res.v7n1p35.

Khairullina, E.R., Valeyev, A. S., Valeyeva, G. K., Valeyeva, N. S., Leifa, A. V., Burdukovskaya, E. A., Shaidullina, A.R. (2015). Features of the Programs Applied Bachelor Degree in Secondary and Higher Vocational Education. Asian Social Science; Vol. 11, No. 3, 213-217, doi:10.5539/ass.v11n4p213.

Mukhametzyanova, G.V. (2010). New Paradigms of Education in training competent professionals. Bulletin of the Moscow State Regional University. Psychological Science, 2, 127.

Muravyova, E. V. (2012). Potential of youth self-management in structure of the safe inhabitancy. Vector Science Togliatti State University, 1, 170.

Novikov, A.M. (2006). Introduction to the methodology of game activity. Publisher "Egves", 48.

Panfilova, A.P. (2006). Training of pedagogical communication. Publishing center "Academy", 336.

Pidkasistyi, P.I. (1996). Technology games in learning and development. Publishing House "High School", 87.

Prokofeva, E.N. (2012). Integrative play in the formation of professional competencies in undergraduate Profile "Protection in emergency situations". Kazan pedagogical journal, 4, 55-56.

Sakhieva, R.G., Khairullina, E.R., Khisamiyeva, L.G., Valeyeva, N.Sh., Masalimova, A.R. \& Zakirova, V.G. (2015). Designing a Structure of the Modular Competence-Based Curriculum and Technologies for Its Implementation into Higher Vocational Institutions. Asian Social Science, Vol. 11, No. 2, 246-251, doi:10.5539/ass.v11n2p246.

Schedrovitsky, G.P. (1982). Organizational - activity games as possible modalities for implementation of ACS. Research Institute OPP APN SSSSR, 29.

Selevko,G.K. (1998). Modern educational technology. Education, 58.

Shaidullina, A.R., Krylov, D.A., Sadovaya, V.V., Yunusova, G.R., Glebov, S.O., Masalimova, A.R. \& Korshunova, I.V. (2015). Model of Vocational School, High School and Manufacture Integration in the Regional System of Professional Education. Review of European Studies, Vol. 7, No. 1, 63-67, doi:10.5539/res.v7n1p63.

Shaidullina, A.R., Masalimova, A.R., Vlasova, V.K., Lisitzina, T.B., Korzhanova, A.A., Tzekhanovich, O.M., Masalimova, A.R. (2014). Education, science and manufacture integration models features in continuous professional education system. Life Science Journal, 11(8s), 478-485.

Shon, D. (1983). Organization learning in Beyond Method: strategies for Social Research. Beverly Hills, CA, 53.

Telegina, N.V., Galimova, E.G \& Masalimova, A.R. (2015).The Structure and Content of the Model of Pedagogical Conditions Binary Approach to Optimization of Control and Diagnostic Functions in Teaching "General pedagogy" to Students. Asian Social 
Science, Vol. 11, No. 1, 364-368, doi:10.5539/ass.v11n1p364.

Verbitsky, AA. (1991). Active Learning in Higher Education: a contextual approach. Publishing House "High School, 207. Vorobiev Y.L. (2006). Basics of creating a culture of safety. Business Express, 316.

Vygotsky, S.L. (1966). The game and its role in the psychological development of the child. Questions psychology, 6, 47. Zeer, E.F.et all (2005). The modernization of vocational education: competence approach. Moscow Publisher MPSI, 216.

Zimnya, I.A. (2006). Competence approach. What is its place in the modern approaches to education? (theoretical and methodological aspect) Journal of Higher education today, 8, 29. 